\section{Cải thiện bám dính giữa các lớp in 3D bê tông bằng hồ xi măng biến tính}

\author{
Trần Văn Miền ${ }^{1,2^{*}}$, Huỳnh Công Tâm ${ }^{1}$, Lê Hoàng Giang ${ }^{1,2}$, Nguyễn Quốc Cường ${ }^{1,2}$ \\ ${ }^{1}$ Khoa Kỹ thuật Xây dựng, Trường Đại học Bách Khoa Thành phố Hồ Chí Minh, 268 Lý Thường Kiệt, Phường 14, Quận 10, Thành \\ phố Hồ Chí Minh \\ ${ }^{2}$ Đại Học Quốc Gia TP.HCM, Phường Linh Trung, Quận Thủ Đức, TP. Hồ Chí Minh
}

\section{TỪ KHÓA}

In 3D bê tông

Độ chảy xòe

Cường độ chịu nén

Cường độ bám dính

Cường độ kéo đứt thử bám dính nền

\section{TÓM TÁ́T}

Bê tông in 3D là một công nghệ hoàn toàn mới, nó được phát triển nhanh chóng thành một kỹ thuật được sử dụng mang nhiều lợi ít trong ngành xây dựng. Nhưng bên cạnh đó, công nghệ bê tông in 3D vẫn tồn tại một vài hạn chế. Trong đó, sự liên kêt bám dính giữa hai lớp bê tông 3D được coi là điểm yếu nhất, nguyên nhân chủ yếu do bề mặt tiếp xúc giữa hai lớp bê tông in bị khô và xuất hiện lỗ rỗng trên bề mặt lớp in bê tông, làm ảnh hưởng đến tính chất cơ học. Bài báo này trình bày nghiên cứu nhằm đưa ra một giải pháp cải thiện bám dính giữa các lớp bê tông in 3D bằng cách sử dụng bốn loại hồ xi măng tạo thành một lớp trung gian giữa các lớp bê tông làm tăng cường độ bám dính và giảm thiểu lỗ rỗng. Các đặc trưng về độ chảy, cường độ chịu nén, cường độ kéo đứt thử bám dính nền cũng được đo để khảo sát phân tích sự tương quan đến cường độ bám dính giữa các lớp bê tông để hiểu sâu về cơ chế bám dính. Kết quả cho thấy, mẫu sử dụng phụ gia Sikament R7N cho kết quả cường độ bám dính giữa các lớp bê tông cao nhất. Ngược lại mẫu sử dụng phụ gia Sika Latex TH cho kết quả thấp hơn mẫu đối chứng.

\section{ABSTRACT}

3D printed concrete is a completely new technology, it was developed rapidly into a technique used to benefit in the construction industry. But besides that, 3D concrete printing technology still has some limitations. In which, interlayer bond of 3D printed concrete is considered the weakest point, the main cause is due to the dry contact surface and the appearance of voids on the interlayer surface affecting the mechanical properties. This paper presents an investigation that offers a solution to improve interlayer bond of 3D printed concrete by using four various cement pastes forming bond interface for the 3D printed layer to increase bond strength and minimize voids. The characteristics of flow, compressive strength, pull - off adhesion strength also measured to investigate and analyze the correlation of interlayer bond strength of 3D printed concrete to understand the adhesion mechanism. The results show that the samples using Sikament R7N additives has the highest interlayer bond strength. In contrast to the samples using Sika Latex TH had lower results than the control sample.

\section{Giới thiệu}

Trong những năm gần đây, nhu cầu phát triển ngày càng tăng ở Việt Nam. Trong đó lượng khí thải carbon và việc lãng phí nguyên vật liệu trong xây dựng đang gia tăng là một những mối quan tâm lớn cho xã hội. Không giống như những ngành công nghiệp khác, ngành công nghiệp xây dựng đang thiếu sự cải tiến về công nghệ. Việc sử dụng ván khuôn gây tốn kém về chi phí, đòi hỏi về một lượng thời gian lắp đặt, nhân công và vật liệu [1]. Để khắc phục vấn đề trên, bê tông in $3 \mathrm{D}$ là một giải pháp xây dựng các kết cấu phức tạp có độ chính xác cao mà không cần đến ván khuôn làm giảm chi phí xây dựng và tăng tốc độ xây dựng [2]. Tuy nhiên, bê tông in 3D phải đối mặt với một trong vấn đề lớn đó là sự thiếu liên kết bám dính giữa các lớp bê tông [3].

Bề mặt của bê tông in 3D sau khi in là khu vực thường xuất hiện vết rạn nứt được xem là điểm yếu chính của liên kết bám dính giữa các lớp bê tông in 3D [4]. Quá trình hydrat hóa diễn ra tại bề mặt giữa các lớp bê tông in 3D làm giảm độ bám dính do không đủ nước dẫn đến bê mặt bị khô [5]. Sự bay hơi ẩm làm khô bề mặt là yếu tố làm ảnh hưởng đến cường độ bám dính giữa hai lớp in [3]. Ảnh hưởng của thời gian trì hoãn của lớp in bê tông càng dài sẽ tạo ra các lỗ rỗng và khoảng trống ở bề mặt liên kết, do hỗn hợp bê tông in phản ứng hydrat hóa làm giảm độ ẩm có trên bề mặt của các lớp in [6]. Ngoài ra, tốc độ in và tỷ lệ cấu trúc cũng ảnh hưởng đến cường độ bám dính giữa các lớp bê tông [5, 7]. Sự liên kết bám dính giữa các lớp bê tông khi không có biện pháp tăng cường được xem là " gót chân Achilles" của bê tông in 3D [8].

Theo lý thuyết liên kết bám dính của vật liệu được phân loại gồm cơ học và hóa học. Trong trường hợp bê tông, liên kết cơ học diễn ra khi lớp phủ xâm nhập vào bề mặt của lớp nền. Quá trình hydrat hóa của xi măng trên bề mặt lớp nền là liên kết hóa học. Cải thiện bám dính giữa hai lớp bê tông bằng cách sử dụng lớp chất kết dính để tạo liên 
kết giữa lớp bê tông cũ và lớp bê tông mới tạo thành mẫu ba lớp [9]. E.Hosseini và cộng sự [10] đã dùng một loại polymer để tăng cường độ bám dính giữa hai lớp bê tông. T.Marchment và cộng sự [11] đã sử dụng hồ xi măng quét lên giữa hai lớp bê tông in 3D để cải thiện cường độ bám dính. Các nghiên cứu cải thiện bám dính giữa các lớp bê tông bằng cách sử dụng một lớp trung gian làm chất liên kết cho thấy sự hiệu quả. Nhưng với tỷ lệ N/XM thấp của lớp trung gian sẽ cho tính công tác thấp khi quét lên bề mặt lớp bê tông 3D được in nhiều lớp dẫn đến khả năng chiều dày lớp bê tông bị biến dạng và có khả năng sụp đổ mẫu in bê tông.

Dựa vào các cơ sở trên, trong bài báo này sẽ khảo sát sử dụng hồ xi măng làm lớp trung gian giữa các lớp bê tông có tính công tác phù hợp để cho các lớp bê tông 3D in được nhiều lớp không bị biến dạng và sụp đổ. Các tính chất độ chảy, cường độ chịu nén, cường độ kéo đứt thử bám dính nền cũng được đo để khảo sát phân tích sự tương quan đến cường độ bám dính giữa các lớp bê tông để hiểu sâu về cơ chế bám dính.

\section{Vật liệu và phương pháp thí nghiệm}

\subsection{Vật liệu thí nghiệm}

\subsubsection{Cấp phối bê tông in $3 D$}

Thành phần chất kết dính được sử dụng trong bê tông in 3D gồm có: xi măng Nghi Sơn PC40 (XM), bột đá vôi MTM 100 của công ty Cổ Phần Khoáng sản Miền Trung (LS) và metacaolanh DG 80 xuất xứ Trung Quốc (MK) với khối lượng riêng lần lượt là $3,05 \mathrm{~g} / \mathrm{cm}^{3}, 2,4 \mathrm{~g} / \mathrm{cm}^{3}$ và $2,7 \mathrm{~g} / \mathrm{cm}^{3}$. Cát sông (C) được sử dụng có khối lượng riêng là $2,6 \mathrm{~g} / \mathrm{cm}^{3}$. Phụ gia hóa học được sử dụng trong nghiên cứu là Sikament R7N của hãng Sika. Cấp phối hỗn hợp bê tông in 3D được thể hiện trong (Bảng 1).

Bảng 1. Cấp phối hỗn hợp bê tông in 3D $\left(\mathrm{kg} / \mathrm{m}^{3}\right)$.

\begin{tabular}{cccccc}
\hline XM & C & LS & MK & N & PG \\
\hline 654,5 & 935 & 93,5 & 187 & 318 & 4,68 \\
\hline
\end{tabular}

\subsubsection{Lớp quét hồ xi măng}

Bốn loại hồ xi măng gốc OPC được sử dụng để làm lớp trung gian để tăng cường bám dính giữa các lớp bê tông. Trong đó có ba loại sử dụng phụ gia của hãng Sika. Tỷ lệ N/XM của bốn loại hồ xi măng được thử nghiệm từ tỷ lệ 0,4 đến 0,6 để chọn ra tỷ lệ đáp ứng các yếu tố sau: tính công tác, không bị phân tầng, tỷ lệ N/XM thấp tối ưu hóa cường độ. Tỷ lệ xem xét và liều lượng sử dụng phụ gia hồ xi măng được trình bày trong (Bảng 2).

\subsection{In hỗn hợp bê tông $3 D$}

Trong nghiên cứu này sử dụng robot 3 trục tọa độ để in hỗn hợp bê tông có vòi in được đặt ở góc $90^{\circ}$, kích thước vòi in cạnh vuông (2x2) cm và tốc độ in là $100 \mathrm{~mm} / \mathrm{s}$. Bê tông in gồm có 12 lớp mỗi lớp có chiều dày $10 \mathrm{~mm}$, in theo hình lập phương, bề rộng của mỗi lớp in là 30 mm như Hình 1 (b). Sau khi trộn hỗn hợp in, bắt đầu in lớp đầu tiên, sau khi hình thành lớp in đầu sử dụng cọ có kích thước rộng $15 \mathrm{~mm}$ quét lớp hồ có chiều dày xấp xỉ $1 \mathrm{~mm}$ lên bề mặt trên của lớp $1,3,5,7,9$ và 11 sau khi lớp bê tông được hình thành Hình 1 (a). Mẫu được chế tạo và dưỡng hộ trong nhiệt độ môi trường $27 \pm 3{ }^{\circ} \mathrm{C}$.

Bảng 2. Tỷ lệ cấp phối và liều lượng phụ gia sử dụng trong hồ xi măng.

\begin{tabular}{|c|c|c|c|c|}
\hline \multirow{2}{*}{$\begin{array}{c}\text { Tên cấp } \\
\text { phối }\end{array}$} & \multirow{2}{*}{$\mathrm{XM}$} & \multirow{2}{*}{$\mathrm{N} / \mathrm{XM}$} & \multicolumn{2}{|c|}{ Phụ gia } \\
\hline & & & Liều lượng & Loại \\
\hline P1 & \multirow{4}{*}{1} & \multirow{4}{*}{$0,4-0,6$} & - & - \\
\hline P2 & & & Thay thế 25 \% nước & Sika Latex TH \\
\hline P3 & & & Thay thế 50 \% nước & Sika Latex TH \\
\hline P4 & & & 0,6 ml/100 g xi măng & Sikament R7N \\
\hline
\end{tabular}

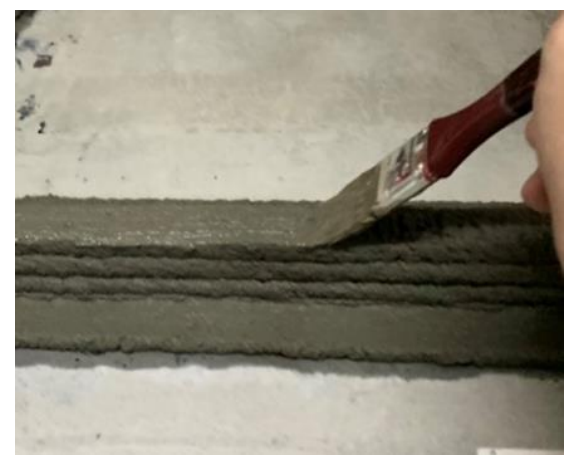

a) Quét lớp hồ xi măng lên bề mặt lớp in

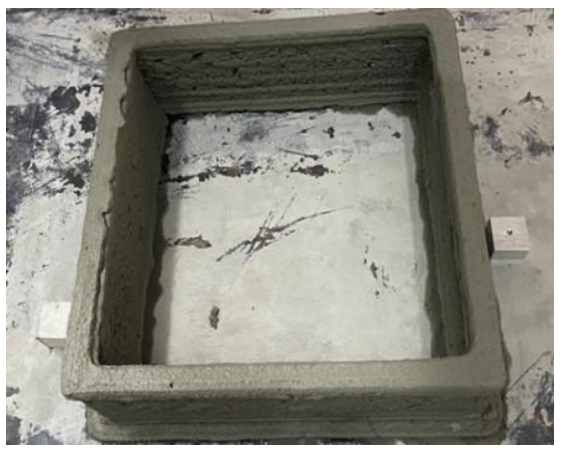

b) Bê tông 3D sau khi in

Hình 1. In bê tông và quét lớp hồ xi măng trên bề mặt bê tông đã in.

\subsection{Phương pháp thí nghiệm}

\subsection{1 Độ chảy xòe}

Tính công tác của các lớp hồ xi măng được đánh giá theo tiêu chuẩn BS EN 12706:2000 [12]. Kích thước của ống thử độ chảy xòe có đường kính $30 \mathrm{~mm}$ và cao $50 \mathrm{~mm}$ như (Hình 2). Thí nghiệm này được thực hiện nhằm mục đích chính là kiểm tra tính công tác của hỗn hợp hồ xi măng từ đó đưa ra sự lựa chọn các tỷ lệ N/XM để tạo lớp trung gian trước khi in lớp kế tiếp.

\subsubsection{Cường độ chịu nén}


Trong nghiên cứu này cường độ chịu nén của các loại hồ xi măng được kiểm tra ở 3,7 và 28 ngày tuổi sau khi dưởng hộ ẩm. Mẫu có kích thước mẫu là (50x50x50) mm, mỗi tổ bao gồm 3 mẫu, tốc độ gia tải 1500 N/s theo tiêu chuẩn ASTM C109 [13].

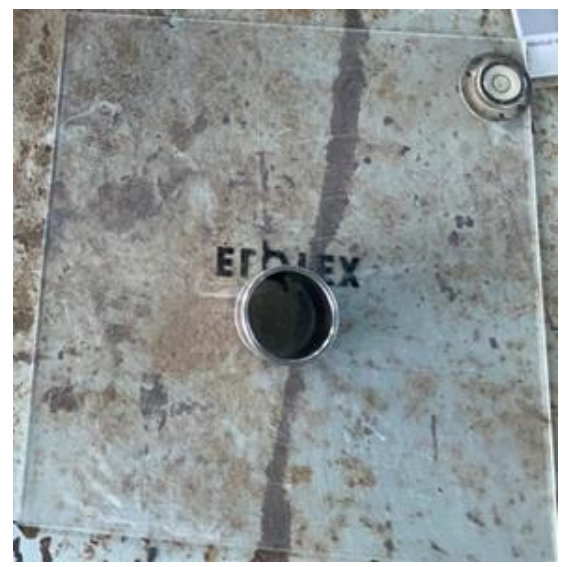

Hình 2. Dụng cụ thí nghiệm đo độ chảy xòe.

\subsubsection{Cường độ kéo đứt thử bám dính nền}

Trong nghiên cứu này cường độ kéo đứt thử độ bám dính nền của bê tông in 3D và các loại hồ xi măng được thí nghiệm theo tiêu chuẩn ASTM D 4541[14] để đánh giá khả năng bám dính của vật liệu trên nền bê tông. Mỗi cấp phối thí nghiệm lấy 3 mẫu hình trụ có đường kính $20 \mathrm{~mm}$, chiều dày lớp thử bám dính là $5 \mathrm{~mm}$ trên tấm nền bê tông không có cốt thép có kích thước (20x30) cm đã đạt cường độ 28 ngày tuổi được thể hiện ở (Hình 3). Thí nghiệm được kiểm tra ở 3,7 và 28 ngày tuổi được bảo dưỡng ở nhiệt độ môi trường $27 \pm 3{ }^{\circ} \mathrm{C}$. Thí nghiệm được thực hiện bằng máy PosiTest AT-M Adhesion Tester.

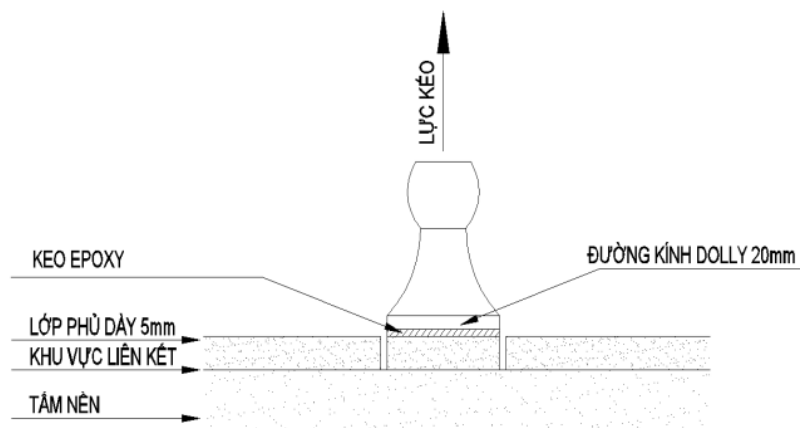

Hình 3. Sơ đồ mô tả kiểm tra kéo đứt thử bám dính nền.

\subsubsection{Cường độ bám dính giữa các lớp bê tông}

Nhằm đánh giá điều kiện ảnh hưởng của các lớp bê tông, lớp 1-2, 3-4, 5-6, 7-8, 9-10 và 11-12 để đơn giản hóa cách ký hiệu lớp lần lượt các lớp được đặt là lớp $1,2,3,4,5$ và 6 . Cường độ bám dính giữa các lớp bê tông được đánh giá bằng thí nghiệm cường độ kéo trực tiếp được dựa theo TCVN 9349-2012 [15]. Để thí nghiệm cường độ bám dính giữa các lớp in, mẫu được cắt có chiều dài $50 \mathrm{~mm}$, sử dụng dolly vuông có kích thước (50x50) mm dán lên bề mặt trên lớp in và mặt dưới được dán vào tấm nền bê tông bằng Sikadur 731 được thể hiện ở Hình 4. Mẫu được kiểm tra ở 3,7 và 28 ngày tuối được bảo dưỡng ở nhiệt độ môi trường $27 \pm 3{ }^{\circ} \mathrm{C}$. Vị trí mẫu thí nghiệm được thể hiện ở Hình 5 . Thí nghiệm được thực hiện bằng máy Matest E142.

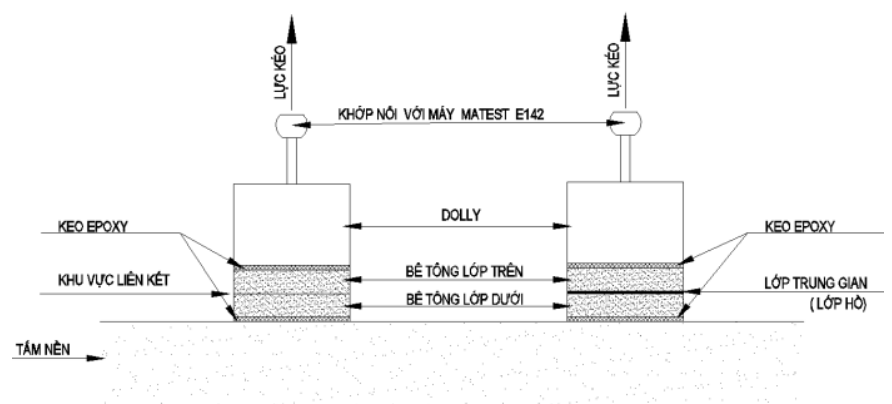

Hình 4. Sơ đồ mô tả kéo bám dính giữa hai lớp bê tông in 3D.

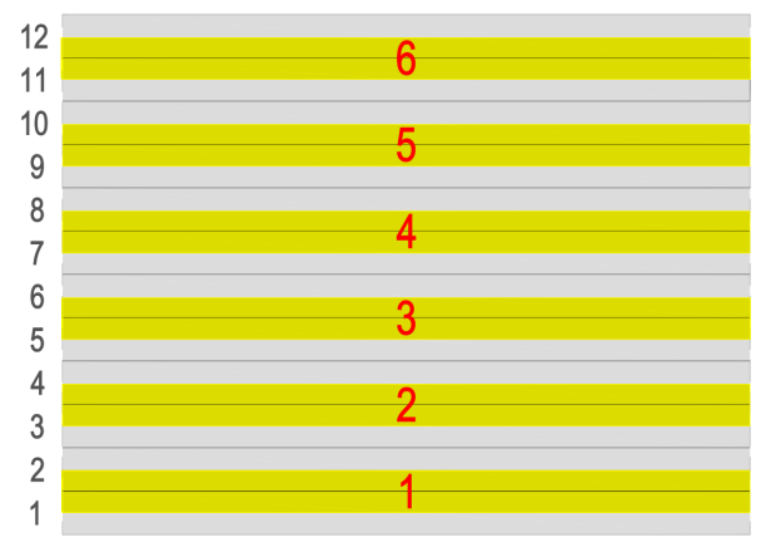

Hình 5. Mô tả vị trí mẫu thí nghiệm.

\section{Kết quả nghiên cứu}

3.1. Đo độ chảy xòe

Độ chảy của hỗn hợp hồ xi măng phụ thuộc chủ yếu vào tỷ lệ $\mathrm{N} / \mathrm{XM}$ là chủ đạo bên cạnh đó hàm lượng, đặc tính loại phụ gia được sử dụng cũng có sự ảnh hưởng lớn. Khi hàm lượng N/XM đạt đến giá trị nhất định lúc này hỗn hợp đạt được các tiêu chí: cường độ, độ dẻo và đặc biệt là tính công tác của hỗn hợp hồ xi măng. Để lý tưởng hóa và gần đúng các đặc tính dòng chảy của hỗn hợp hồ xi măng được thực hiện bằng cách đo trung bình cộng đường kính lớn nhất vuông góc nhau. Dựa vào số liệu biểu đồ (Hình 6) ta thấy ảnh hưởng của tỷ lệ $\mathrm{N} / \mathrm{XM}$ 0,4 - 0,6 đến độ chảy xòe của các mẫu $\mathrm{P} 1, \mathrm{P} 2, \mathrm{P} 3$ và $\mathrm{P} 4$.

Ở tỷ lệ $\mathrm{N} / \mathrm{XM}$ đầu tiên 0,4 kết quả lần lượt các mẫu P1, P2, P3 và $\mathrm{P} 4$ có đường kính là $3,1 \mathrm{~cm} ; 8,5 \mathrm{~cm} ; 13 \mathrm{~cm}$ và $8,2 \mathrm{~cm}$ đã cho thấy sự khác biệt, trong đó $\mathrm{P} 1$ cho kết quả thấp nhất vì không sử dụng phụ gia, ngược lại hỗn hợp P2 ( thay thế nước 50 \% Sika Latex TH) cho kết quả cao nhất. Mẫu P2, P3 và P4 lần lượt ở tỷ lệ N/XM tương ứng 0,52; 0,48 và 0,56 trở lên bắt đầu xuất hiện hiện tượng tách nước phụ gia 
nổi lên bề mặt. Hiện tượng tách nước dẫn đến sự phân bố của các sản phẩm hydrat hóa không đồng đều trong hỗn hợp. Độ chảy xòe thấp ảnh hưởng đến tính công tác dẫn đến khả năng lớp bê tông in bị biến dạng hình học và dẫn đến tình trạng bị sụp đổ khi lớp bê tông tiếp theo chồng lên. Bên cạnh đó độ chảy xòe thấp làm giảm khả năng lèn của lớp hồ xi măng vào bề mặt lỗ rỗng của lớp bê tông được hình thành dẫn đến làm giảm khả năng bám dính giữa các lớp bê tông. Dựa vào các tiêu chí trên các loại hồ xi măng P1, P2, P3 và P4 lựa chọn các tỷ lệ lần lượt là 0,6 ; 0,$48 ; 0,44$ và 0,52 có đường kính độ chảy xòe như (Hình 7).

\subsection{Cường độ bám dính giữa các lớp bê tông in $3 D$}

Kết quả cường độ bám dính giữa các lớp in bê tông của các mẫu đối chứng $3 \mathrm{DP}$ và 4 mẫu sử dụng lớp hồ xi măng làm lớp trung gian $\mathrm{P} 1, \mathrm{P} 2, \mathrm{P} 3$ và $\mathrm{P} 4$ ở 3,7 và 28 ngày tuổi được trình bày ở (Hình 8 ). Tại 3 ngày tuổi, cường độ bám dính giữa các lớp in bê tông của các mẫu sử dụng lớp quét hồ xi măng đa số cho kết quả thấp hơn mẫu đối chứng
3DP không sử dụng lớp quét hồ. Ngoại trừ mẫu sử dụng lớp quét hồ P1 có kết quả cao hơn mẫu 3DP nhưng không quá chênh lệch cụ thể P1: 1,58 MPa và 3DP: $1,57 \mathrm{MPa}$.

Ở 7 và 28 ngày tuổi có sự cải thiện cường độ bám dính giữa các lớp bê tông. Trong đó, mẫu P1 và P4 có xu hướng cao hơn mẫu 3DP. Ngoại trừ mẫu P2 và P3 thì lại cho kết quả thấp hơn mẫu 3DP. Cụ thể ở 28 ngày tuổi, cường độ bám dính giữa các lớp in bê tông mẫu $\mathrm{P} 1$ và $\mathrm{P} 4$ cho kết quả cao hơn mẫu đối chứng 3DP lần lượt là 9,09 \% và 14,14 \%. Đối với mẫu sử dụng lớp quét hồ $\mathrm{P} 2$ và $\mathrm{P} 3$ vẫn có xu hướng cường độ bám dính thấp hơn mẫu 3DP lần lượt là $21,72 \%$ và 13,13 \%. Mẫu sử dụng lớp quét hồ $\mathrm{P} 2$ vẫn cho kết quả cường độ bám dính giữa các lớp bê tông thấp nhất ở 28 ngày tuổi là 1,55 MPa. Mẫu sử dụng lớp quét hồ P4 cho kết quả cường độ bám dính giữa các lớp bê tông cao nhất ở 28 ngày tuổi là 2,26 MPa. Kết quả tương tự cho thấy khi dùng phụ gia có chất kéo dài ninh kết làm lớp quét trung gian đều có cường độ bám dính giữa các lớp bê tông in 3D cao hơn mẫu đối chứng [11].

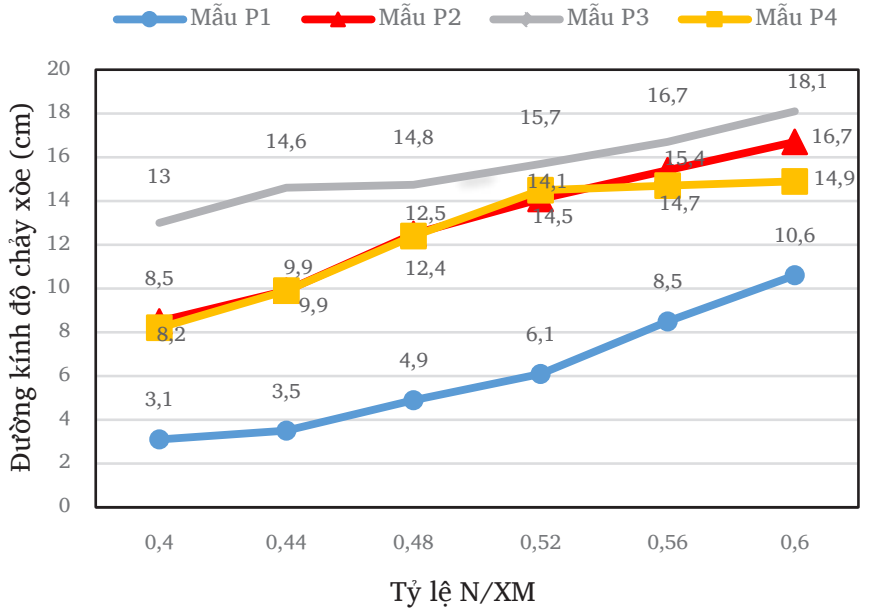

Hình 6. Ảnh hưởng của tỷ lệ $\mathrm{N} / \mathrm{XM}$ từ 0,4 đến 0,6 đến đường kính độ

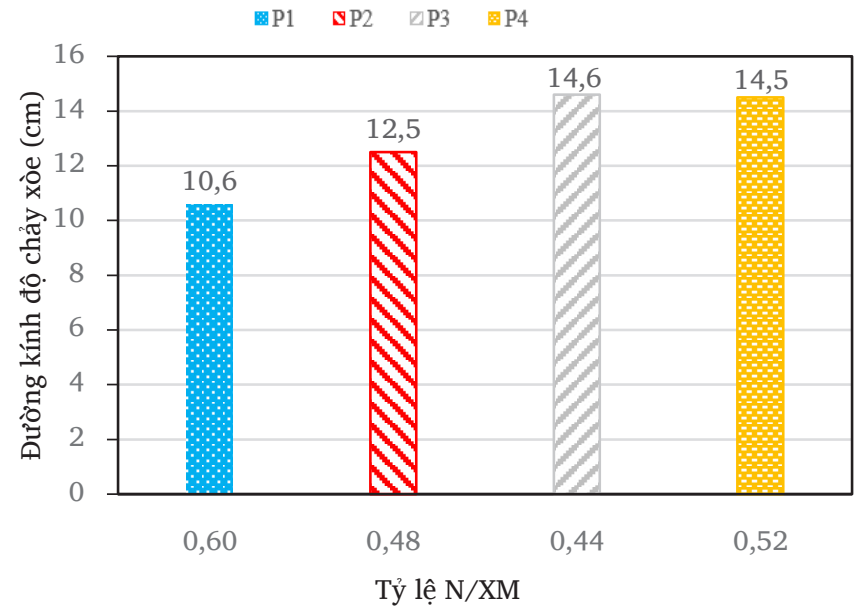

Hình 7. Đường kính độ chảy xòe của mẫu P1, P2, P3 và P4. chảy xòe.

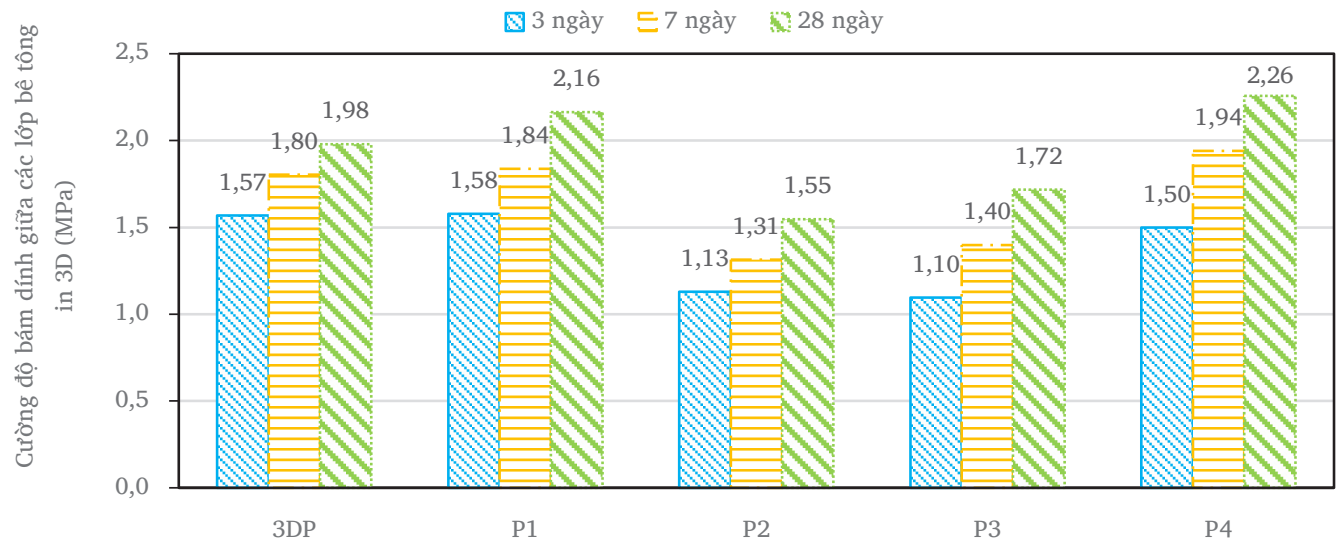

Hình 8. Cường độ bám dính giữa các lớp bê tông in 3D ở 3,7 và 28 ngày tuổi. 
3.3. Mối tương quan giữa độ chảy xòe đến cường độ bám dính giữa các lớp bê tông in $3 D$

Độ chảy của các loại hồ xi măng phụ thuộc vào tỷ lệ N/XM và hàm lượng phụ gia sử dụng. Như được thể hiện trong (Hình 7) các mẫu $\mathrm{P} 1, \mathrm{P} 2, \mathrm{P} 3$ và $\mathrm{P} 4$ được xem xét độ chảy xòe có mối tương quan cường độ bám dính giữa các lớp bê tông in 3D trong (Hình 9) ở 28 ngày tuổi. Đường kính độ chảy cao đảm bảo cho tính công tác, dễ lèn lấp đầy lỗ rỗng và tạo độ ẩm cho bề mặt lớp bê tông in trước đồng thời còn làm tăng diện tích bề mặt tiếp xúc giữa hai lớp in. Kết quả cho thấy mẫu ở 28 ngày tuổi có sử dụng lớp quét hồ $\mathrm{P} 4$ có đường kính độ chảy xòe là $14,5 \mathrm{~cm}$ có kết quả không quá chênh lệch với mẫu có P3, nhưng cho kết quả cường độ bám dính giữa các lớp bê tông cao nhất là 2,26 MPa.
Trong đó, cường độ bám dính của mẫu $\mathrm{P} 3$ có kết quả là 1,72 MPa thấp hơn mẫu 3DP, $\mathrm{P} 1$ và $\mathrm{P} 4$. Bên cạnh đó, mẫu $\mathrm{P} 1$ có đường kính độ chảy xòe là 10,6 cm thấp hơn mẫu $\mathrm{P} 2$ và $\mathrm{P} 3$, nhưng ngược lại cho kết quả cường độ bám dính cao hơn là 2,16 MPa.

Qua kết quả trên có thể giải thích không chỉ có độ chảy cao ảnh hưởng đến cường độ bám dính giữa các lớp bê tông mà còn phụ thuộc vào loại phụ gia sử dụng, khả năng giữ ẩm cũng là một yếu tố quan trọng. Quá trình hydrat hóa được xem là làm tăng tốc độ bay hơi của độ ẩm trên bề mặt làm ảnh hưởng đến cường độ bám dính. Mẫu P4 sử dụng phụ gia có tính năng kéo dài thời ninh kết làm giảm nhiệt hydrat hóa của xi măng, duy trì độ ẩm bề mặt cho nên có cường độ bám dính giữa các lớp bê tông cao hơn.

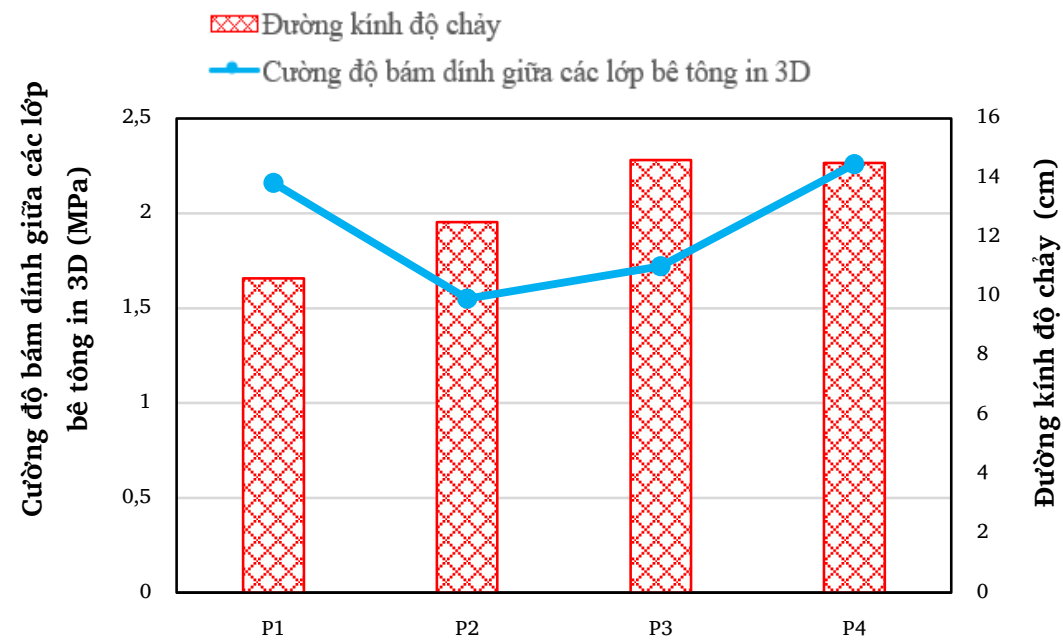

Hình 9. Đường kính độ chảy xòe và cường độ bám dính giữa các lớp bê tông in 3D ở 28 ngày tuổi.

\subsection{Mối tương quan giữa cường độ chịu nén đến cường độ bám dính giữa các lớp bê tông in $3 D$}

Trong kết cấu xây dựng bê tông làm việc tốt nhất ở trạng thái chịu nén. Do đó chỉ tiêu tính chất quan trọng trong bê tông là cường độ chịu nén. Cường độ bê tông càng cao độ rỗng bên trong cấu trúc giảm, lúc này diện tích liên kết bám dính cũng sẽ tăng. Nhưng cường độ chịu nén trong (Hình 10 ) ở 3,7 và 28 ngày tuổi cho kết quả ngược lại. Tỷ lệ $\mathrm{N} / \mathrm{XM}$ và liệu lượng phụ gia sử dụng cho thấy ảnh hưởng đến cường độ chịu nén. Mẫu P3 có tỷ lệ N/XM thấp nhất nhưng liều lượng phụ gia Sika Latex TH sử dụng thay thế nước 50 \% làm giảm cường độ chịu nén kết quả cho thấy tương tự khi sử dụng phụ gia có polymer [16]. Cụ thể hơn ở 28 ngày tuổi (Hình 11) mẫu $\mathrm{P} 2$ có cường độ chịu nén cao nhất là 52,6 $\mathrm{MPa}$, nhưng kết quả cường độ bám dính lại chỉ có 1,55 MPa thấp hơn các mẫu P1, P3 và $\mathrm{P} 4$ có kết quả lần lượt là 2,16 $\mathrm{MPa}, 1,72 \mathrm{MPa}$ và 2,26 $\mathrm{MPa}$. Đối với mẫu P4 có kết quả cường độ nén thấp hơn mẫu P2 nhưng lại cho cường độ bám dính giữa các lớp bê tông cao nhất là 2,26 MPa.

Các mẫu lớp quét hồ $\mathrm{P} 1, \mathrm{P} 2, \mathrm{P} 3$ và $\mathrm{P} 4$ khi so sánh cường độ nén với cường độ bám dính có thể giúp ta nhận thấy cường độ nén cao nhưng lại không cho cường độ bám dính cao. Kết quả này cho thấy sự tương tự của nghiên cứu trước đây của T.Marchment và cộng sự [11]. Vì cường độ bám dính còn phụ thuộc nhiều yếu tố như loại phụ gia sử dụng, độ ẩm bề mặt v.v...

3.5. Mối tương quan giữa cường độ kéo đứt thử bám dính nền đến cường độ bám dính giữa các lớp bê tông in $3 D$

Trong nghiên cứu cường độ kéo đứt thử độ bám dính nền của bê tông in 3D và các loại hồ xi măng được thí nghiệm để đánh giá khả năng bám dính của vật liệu trên nền bê tông đã đạt 28 ngày tuổi. Các mẫu thí nghiệm cường độ kéo đứt thử độ bám dính nền bê tông qua các lỗ rỗng mao quản, với đặc tính tăng liên kết bám dính của mẫu sử dụng phụ gia Sika Latex TH P2 và P3 đã cho cho thấy kết quả ở (Hình 12) vượt trội hơn các mẫu 3DP, $\mathrm{P} 1$ và $\mathrm{P} 4$ ở 3,7 và 28 ngày tuổi. Trong đó, mẫu P3 kết quả cường độ kéo đứt thử độ bám dính nền là 3,62 MPa cao hơn các mẫu còn lại.

Cường độ kéo đứt thử bám dính nền "liên kết lạnh" và cường độ bám dính giữa các lớp bê tông "liên kết nóng" về mặt thí nghiệm thì là hai hình 
thức liên kết bám dính khác nhau. Mối quan hệ của cường độ kéo đứt thử bám dính nền đến cường độ bám dính giữa các lớp bê tông in 3D ở độ tuổi 28 ngày được thể hiện ở (Hình 13). Trong đó, mẫu P3 cho kết quả cường

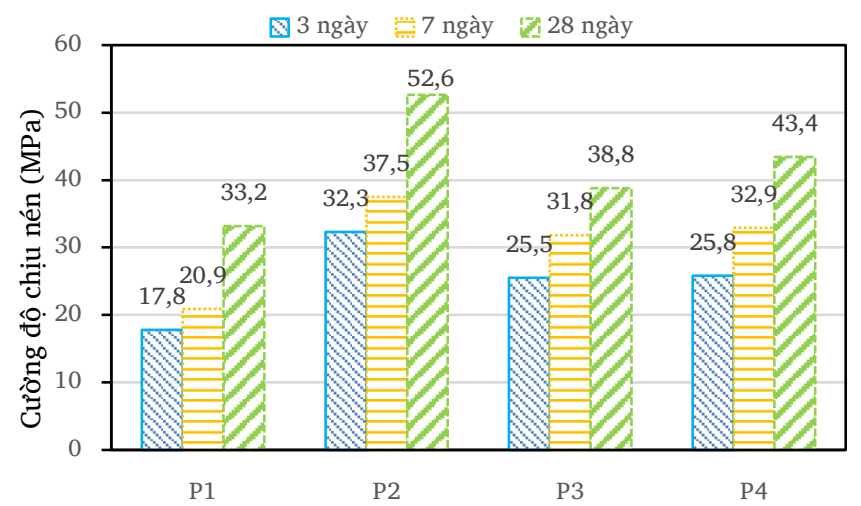

Hình 10. Cường độ chịu nén của các mẫu $P 1, P 2, P 3$ và $P 4$ ở 3,7 và 28 ngày tuổi. độ "liên kết lạnh" cao nhất ở 28 ngày tuổi là 3,62 MPa. Tuy nhiên đối với kết quả cường độ "liên kết nóng" mẫu P3 là 1,72 MPa thấp hơn mẫu đối chứng 3DP.

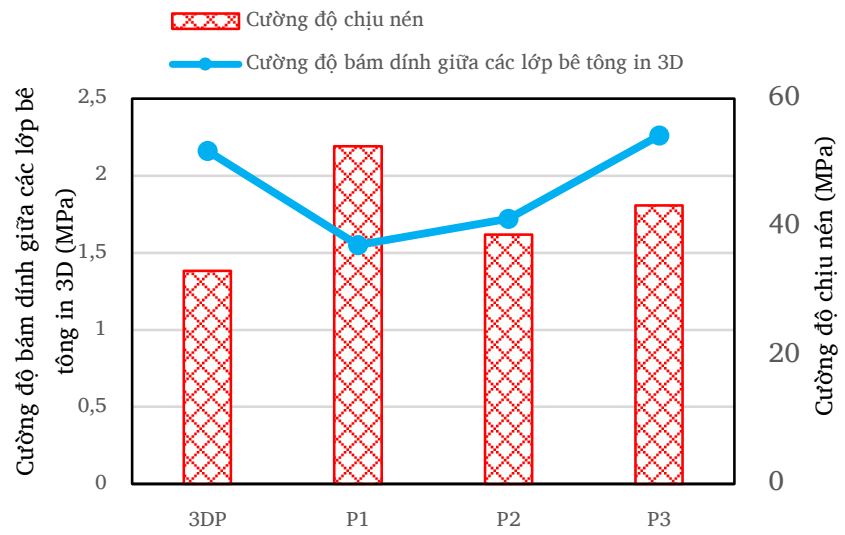

Hình 11. Cường độ chịu nén và cường độ bám dính giữa các lớp bê tông in 3D ở 28 ngày tuổi.

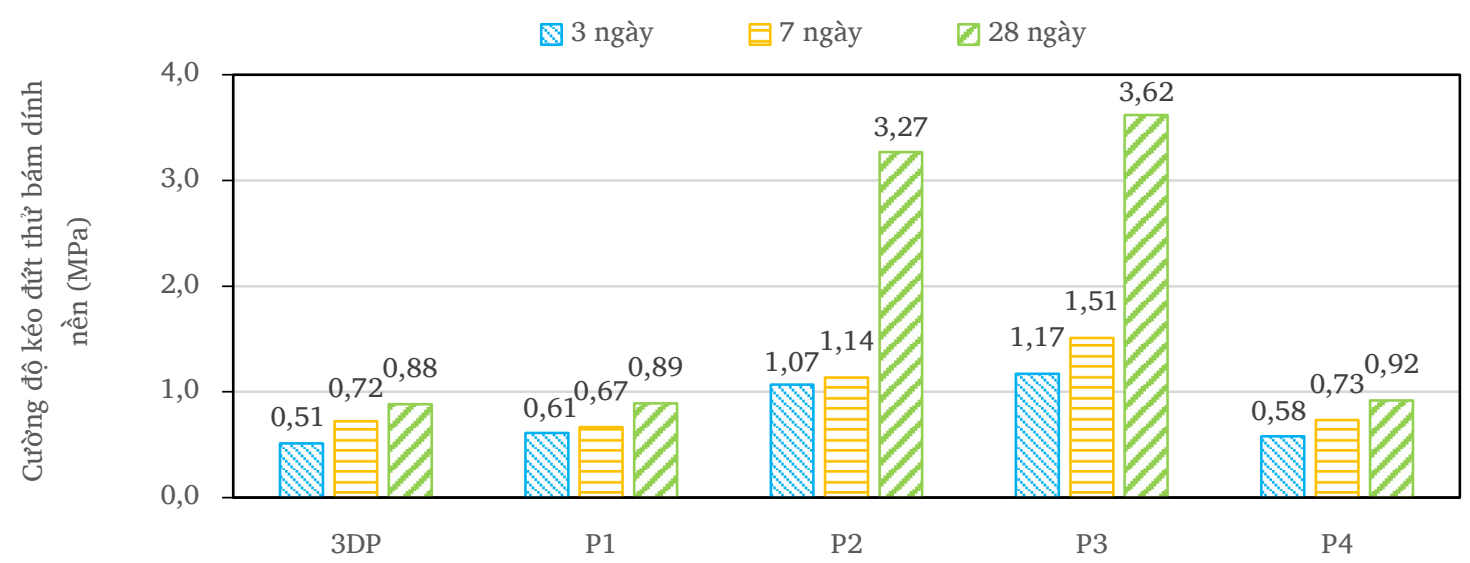

Hình 12. Cường độ kéo đứt thử bám dính nền ở 3,7 và 28 ngày tuổi.

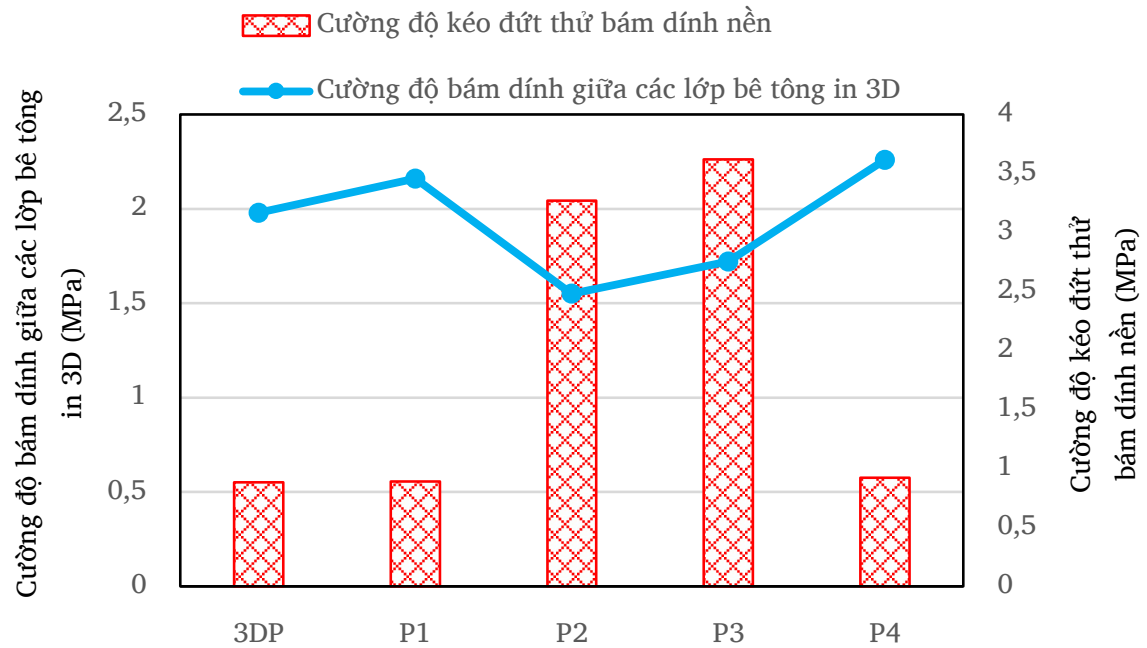

Hình 13. Cường độ kéo đứt thử bám dính nền và cường độ bám dính giữa các lớp bê tông in 3D ở 28 ngày tuổi. 


\section{Kết luận}

Nghiên cứu này mục đích cung cấp giải pháp, phân tích vấn đề cải thiện bám dính giữa các lớp in 3D bê tông. Sử dụng các loại hồ xi măng tạo thành một lớp trung gian giữa các lớp bê tông làm tăng diện tích tiếp xúc và giảm thiểu lỗ rỗng. Thông qua các kết quả thực nghiệm, có thể rút ra các kết luận sau:

- Độ chảy xòe cao của hồ xi măng sẽ ảnh hưởng đến tính công tác của hỗn hợp, quá trình thi công lớp quét sẽ diễn ra dễ dàng hơn nếu hỗn hợp có độ chảy xòe cao. Bên cạnh đó phụ gia kéo dài thời gian ninh kết giúp duy trì độ ẩm bề mặt lớp bê tông in từ đó cho ta kết quả cường độ bám dính giữa các lớp bê tông in được cải thiện.

- Cường độ chịu nén dùng để đánh giá độ đặc chắc của hồ xi măng từ đó tìm mối tương quan về cường độ bám dính giữa các lớp bê tông. Qua quan sát có thể thấy rằng Cường độ chịu nén cho thấy có xu hướng tương tự như độ chảy xòe.

- Cơ chế liên kết của hai thí nghiệm có sự khác biệt về "liên kết nóng" và "liên kết lạnh" để đánh giả khả năng bám dính của vật liệu. Mẫu P3 cho kết quả thí nghiệm cường độ kéo đứt thử bám dính nền "liên kết lạnh" cao hơn các mẫu còn lại ở các độ tuổi 3,7 và 28 ngày, nhưng ở thí nghiệm cường độ bám dính giữa các lớp bê tông cho kết quả thấp hơn các mẫu 3DP, P1 và P4 có kết quả lần lượt là 1,98 $\mathrm{MPa}, 2,16 \mathrm{MPa}$ và 2,26 MPa.

- Trong các loại hồ xi măng sử dụng thì mẫu P4 dùng Sikament R7N với tỷ lệ N/XM 0,52 mang lại hiệu quả cho việc cải thiện bám dính giữa các lớp bê tông in 3D tốt hơn. Trong khi đó, mẫu sử dụng Sika Latex TH không mang lại hiệu quả cao trong việc cải thiện bám dính giữa các lớp bê tông in 3D.

Việc sử dụng các loại lớp quét hồ tạo lớp trung gian giữa các lớp bê tông cho thấy có sự cải thiện về cường độ bám dính. Tuy nhiên, việc sử dụng một số loại phụ gia có thể làm giảm cường độ bám dính giữa các lớp bê tông. Không chỉ độ chảy cao của các lớp hồ là ảnh hưởng đến cường độ bám dính giữa các lớp bê tông nhưng cường độ bám dính giữa các lớp bê tông lại phụ thuộc vào độ ẩm của bề mặt, các yếu tố hấp thụ nước, phân tán các hạt xi măng, quá trình hydrat hóa và loại phụ gia sử dụng.

\section{Tài liệu kham khảo}

[1]. G.D.Schutter, K.Lesage, V.Mechtcherine, V.N.Nerella, G.Habert, I.AgustiJuan, "Vision of 3D printing with concrete - Technical, economic and environmental potentials, "Cement and Concrete Research journal, pp. 2536,2018. Doi: 10.1016/j.cemconres.2018.06.001.

[2]. T.Wangler, E.LIoret, L.Reiter, N.Hack, F.Gramazio, M.Kohler, M.
Bernhard, B.Dillenburger, J. Buchli, N.Roussel and R.Flatt, "Digital Concrete: Opportunities and Challenges," RILEM Technical Letters, pp. 1: 67 - 75, 2016, Doi: 10.21809/rilemtechlett.2016.16.

[3]. J.G.Sanjayan, B.Nematollahi, M.Xia and T.Marchment, "Effect of surface moisture on inter-layer strength of 3D printed concrete," Construction and Building Materials, vol. 172. pp. 468-475, 2018, Doi: 10.1016/j.conbuildmat.2018.03.232.

[4]. T.T.Le, S.A.Austin, S.Lim, R.A.Buswell, A.G.F.Gibb and T.Thorpe, "Mix design and fresh properties for high-performance printing concrete," Materials and Structures, pp. 45:1221-1232, 2012, Doi: 10.1617/s11527012-9828-z.

[5]. E.Keitaa, H.Bessaies-Beyb, W.Zuoa, P.Belina and N.Roussel, "Weak bond strength between successive layers in extrusion-based additive manufacturing: measurement and physical origin." Cement and Concrete Research, 2019, Doi: 0.1016/j.cemconres.2019.105787.

[6]. Y.W.D.Tay, G.H.A.Ting, Y.Qian, B.Panda, L.He and M.J.Tan, “Time gap effect on bond strength of 3D-printed concrete," Virtual and Physical Prototyping, pp. 1-10, 2018, Doi:10.1080/17452759.2018.1500420.

[7]. J.V.D.Putten, M.Deprez, V.Cnudde, G.D.Schutter and K.V.Tittelboom, "Microstructural characterization of 3D Printed cementitious materials." Materials, 2019, Doi: :10.3390/ma12182993.

[8]. V.N.Nerella, S.Hempel and V.M.Technische, "Micro-and Macroscopic investigations on the interface between layers of 3D-Printed cementitious elements," International conference on Advances in construction materials and systems, pp. 3-8, 2017.

[9]. G.Li, "A new way to increase the long-term bond strength of new-to-old concrete by the use of fly ash," Cement and Concrete Research, vol. 33, no. 6. pp. 799-806, 2003, Doi: 10.1016/S0008-8846(02)01064-5.

[10]. E.Hosseini, M.Zakertabrizi, A.H.Korayem and G.Xu, "A novel method to enhance the interlayer bonding of 3D printing concrete: An experimental and computational investigation," Cement and Concrete Composites, vol. 99. pp. 112-119, 2019, Doi: 10.1016/j.cemconcomp.2019.03.008.

[11]. T.Marchment, J.Sanjayan and M.Xia, "Method of enhancing interlayer bond strength in construction scale 3D printing with mortar by effective bond area amplification." Materials and Design, 2019,

Doi: 10.1016/j.matdes.2019.107684.

[12]. BS EN 12706:2000, "Adhesives test methods for hydraulic setting floor smoothing and/or levelling compounds - Determination of flow characteristics," 2000.

[13]. ASTM C109/C109M-02, "Standard test method for compressive strength of hydraulic cement mortars," Annual Book of ASTM Standards, vol. 04, pp. 1-6, 2002.

[14]. ASTM D4541-09, "Standard test method for pull-off strength of coatings using portable adhesion testers." ASTM International, 2009.

[15]. TCVN 9349:2012, "Lớp phủ mặt kết cấu xây dựng - Phương pháp kéo đứt thử độ bám dính nền," 2012.

[16]. A.S.Ali, H.S.Jawad and I.S.Majeed, "Improvement the properties of cement mortar by using styrene butadiene rubber polymer," Journal of Engineering and Development, vol.16, no.3, 2012. 